\title{
深海信息体系构想及关键技术
}

\author{
夏学知，陈雁飞, 曹江丽 \\ （中国船舶重工集团有限公司第七O九研究所，武汉 430074）
}

摘要: 深海资源开发和科学研究涉及的深海作业任务中, 信息体系是深海装备协同并发挥体系作用的关键因素。本文分析了 构建深海信息体系以支撑装备协同环境的需求, 探讨了信息体系的构成要素、面临问题、构建重点和关键技术, 从加强顶层 规划、聚焦关键技术、适时示范应用等角度给出了深海信息体系的发展建议。

关键词：深海利用；信息体系；体系构建；智能化

中图分类号: TP399 文献标识码: A

\section{Conception and Key Technologies of Deep-Sea Information System}

\author{
Xia Xuezhi, Chen Yanfei, Cao Jiangli
}

(The 709 Research Institute of China Shipbuilding Industry Group Co., Ltd., Wuhan 430074, China)

\begin{abstract}
The deep-sea information system can facilitate deep-sea equipment collaboration and plays a systematic role when being applied to deep-sea resource exploitation and research. This paper analyzes the demand for building a deep-sea information system to support the collaborative environment of equipment, and explores the elements, focus, major challenges, and key technologies of the deep-sea information system. To promote the development of the deep-sea information system, we propose strengthening top-level planning, focusing on key technologies, and conducting timely demonstration applications.
\end{abstract}

Keywords: deep-sea utilization; information system; system construction; intelligence

一、前言

深海因其具有丰富的资源、广阔的空间，以及 所蕴藏的巨大的政治、经济、军事、科研和生态环 境价值, 成为 21 世纪大国必争之地。随着人类对 海洋开发需求的不断增长, 以及物联网、云计算、 大数据、移动互联等新一代信息技术的快速发展,
利用信息技术提高人类 “认识海洋、经略海洋、管 控海洋” 的能力已经成为推进海洋事业发展的重要 动力。我国将处理好海洋军事、经济和科技的关系, 选择走合作、开放的道路, 通过科技先行力求脱颖 而出, 争取海上的引领地位 [1]。

在民用领域, 传统海洋强国一直注重开展海洋 开发的 “蓝色圈地” 运动。美国牢牢占据着深海活

收稿日期 : 2019-06-24; 修回日期 : 2019-10-25

通讯作者: 夏学知, 中国船舶重工集团有限公司第七O九研究所研究员, 主要研究方向为信息工程、指控系统; E-mail: xzxia@vip.163.com 资助项目：中国工程院咨询项目 “海洋强国战略研究 2035” (2018-ZD-08)

本刊网址： www.engineering.org.cn/ch/journal/sscae 
动的主导地位, 是目前深海资源拥有量最大、开发 技术研究水平最高的国家。日本出于战略资源需求 的考虑，近年来在深海金属矿、天然气水合物、深 海生物基因的勘查 / 开发 / 科研方面的投资力度已 居世界第一。韩国、印度等新兴工业国家也在积极 参与区域海底资源的争夺, 例如: 韩国于 1998 年 研制成功了 $6000 \mathrm{~m}$ 水下机器人, 已在太平洋有关 海域进行热液硫化物和富钴结壳矿区的选区调查; 印度投入了大量资源用于深海开发 [2]。

在军事领域, 深海空间由于通透性差、压力变 化大、水文特性复杂等特点而使其难以感知, 易于 遂行隐蔽性和突然性任务, 成为继陆、海、空、天、 电磁之后的第 6 维重要战略空间 $[3,4]$ 。以深海基地 为中心、以深海预警和通信系统为依托、以深海后 勤体系为保障、以隐蔽性综合打击为手段, 由此构 成体系化的深海军事力量, 可以充分发挥深海作战 效能, 有望颠覆传统海战模式 [5]。美国在潜艇平 台、水下无人系统、海底监视系统、反潜装备等多 方面都处于世界领先水平 [6 10], 朝着组建深海部 队、完善深海作战条例、发展深海武器系统的方向 发展。俄罗斯长期将潜艇平台和水下作战能力视为 维持海上非对称军事平衡的重要手段, 持续发展新 型潜艇、水下推进、综合探测等装备和技术，着力 提升其深海军事力量。

海洋强国从 20 世纪五六十年代起, 通过深海 的探测、通信、导航、信息利用等方面的技术综合 与创新, 逐步构建深海立体信息体系, 重点发展贯 穿深海、浅海、海面、空中、太空、电磁等空间的 综合信息保障能力。围绕海洋信息系统建设, 国际 组织及美国、欧洲、日本等世界海洋强国或地区, 纷纷投入巨资实施了一系列重大项目，包括：全球 海洋实时观测网计划 (ARGO)、一体化海洋观测系 统 (IOOS)、海王星海底观测网络计划 (NEPTUNE)、 欧洲海底观测网（ESONET）、密集型地震海啸海 底监测网系统（DONET）等。

近年来, 我国逐步开展并深入实施深海大洋科 学调查、资源勘探开发、战略资源防护等海洋权益 利用和维护工作, 由此对 “认识海洋、经略海洋、 管控海洋” 提出了全新的要求。与之对应, 海洋信 息化建设及应用成为亟需重点发展的领域, 深海信 息化与智慧化也成为 “数字海洋” 的重要发展方 向 [11]。随着大深度载人平台、无人运载器、深海
预置装置等大型海洋装备的研制成功和陆续投入应 用, 同步规划发展深海信息体系、开展深海信息化 建设, 已成为当务之急。

\section{二、面临问题}

深海信息体系是由功能上相互联系、相互作用, 性能上相互补充的多种信息设施组成, 其体系要素 (各类感知装置、作业平台、作业指挥调度管理功 能系统等）通过多种通信手段互联互通，并与岸基、 空中、水面的其他平台/系统互连互通, 形成具备 广域信息获取、处理、共享的体系, 由此保障深海 作业人员 / 平台对信息获取与利用的需求。

深海信息体系需要面向军民应用需求, 整合各 类信息资源，提升深海信息感知和共享能力。受深 海物理场特性和深海装备能力限制, 深海信息体系 构建面临着一系列难点问题（见表 1)。

\section{三、初步设想}

聚焦深海信息的观测、利用、管理和保障需求, 提出了深海信息体系建设的初步设想。深海信息体 系包含深海信息感知、深海信息传输、深海作业管 理、深海综合保障、深海安防 5 个方面, 涉及的要 素有: 依附深海平台/单元的探测、通信、导航、 指挥控制、支援保障等设施, 依附深海及海底的探 测、导航、通信等设施，信息、法规、条令等外部 资源。

(1) 深海信息感知系统主要由海底固定、深海 浮标、深海平台（有人 / 无人）配置的各类传感器 组成, 具备水声、光学、电磁场等多类信息收集与 感知能力, 用于平时水下环境信息收集和水下目标 的侦听、水下探测, 以满足对特定深海区域的全天 候、全频域信息感知需求。还可与海面和空中甚 至天基感知体系互联，在更大体系层面发挥感知 作用。

（2）深海信息传输系统主要由海底固定光纤通 信、水下甚低频（VLF）和超低频（SLF）通信、 水下无线射频通信、水声扩频通信、水下激光通信、 水下中微子通信等设备, 以及浮标式数据链和卫星 通信天线等组成。用于深海感知和控制信息的传 输, 以及与海面、空中、岸基和天基信息系统的 
表 1 深海信息体系构建的主要难点

\begin{tabular}{|c|c|c|}
\hline 主要难点 & 约束因素 & 对体系构建的影响 \\
\hline 体系资源有限 & $\begin{array}{l}\text { 多数深海单元载荷小、平台规模受限、支援保 } \\
\text { 障不足 }\end{array}$ & 体系规模小、海域控制范围有限 \\
\hline 感知能力有限 & $\begin{array}{l}\text { 水下探测、识别、警戒范围、威胁辨识能力 } \\
\text { 受限 }\end{array}$ & 难以准确把握深海环境和态势 \\
\hline 导航定位手段有限 & 导航定位方式少, 精度不高 & $\begin{array}{l}\text { 难以在大范围内准确定位, 影响作业规划、航 } \\
\text { 路规划和航线安全 }\end{array}$ \\
\hline 通信能力有限 & 距离近、速率不高、方式少 & $\begin{array}{l}\text { 有人 / 无人协同、无人自主协同等难以实施, } \\
\text { 无人集群规模受限 }\end{array}$ \\
\hline 平台信息管理能力受限 & $\begin{array}{l}\text { 平台计算能力与能耗受限, 智能信息处理、决 } \\
\text { 策、控制智能化程度有限 }\end{array}$ & $\begin{array}{l}\text { 作业动态规划、指挥控制能力不足, 系统智能 } \\
\text { 化、体系智能化程度难以提高 }\end{array}$ \\
\hline 综合保障有限 & 电力保障、设备保障受限 & 体系规模、持久性受影响 \\
\hline 安全防护欠缺 & 长期无人值守, 缺乏攻击感知与防护能力 & 平台及体系的安全性有限, 易受破坏和攻击 \\
\hline 基础数据不足 & $\begin{array}{l}\text { 法规标准, 海底地形、洋流、生物生态、地质 } \\
\text { 构造等信息掌握有限 }\end{array}$ & 限制作业规划、自主航行等 \\
\hline
\end{tabular}

互联互通。

(3) 深海作业管理系统主要包括深海空间站、 无人水下航行器 (UUV) 和自主式水下航行器 (AUV)、深海预置装置、深海作业工具以及作业 管理和指挥控制系统。深海空间站载荷能力大 (数 百至数千吨), 可以携带功能广泛的作业潜水器及 作业工具在 1000 3000 m 水域进行深海工程作业。 UUV 和 AUV 具有轻型、中型和重型多个类别, 可 以执行海洋调查、海洋探测、水下运输、布雷与猎 雷、情报侦察等任务。深海预置装置可为深海移动 平台提供能源补给、导航定位与对时条件。深海作 业工具是拓展深海运载器作业能力、提升深海科学 考察能力的重要手段, 可以根据具体的探索任务、 科研目标来进行差异化配置。作业管理和指挥控制 系统是构建深海信息体系的核心，部署于深海作业 平台, 执行体系资源综合管控、多源信息处理、综 合信息管理、单平台/集群作业指挥调度、作战指 挥控制、安全防卫管控等任务。

（4）深海综合保障系统主要包括海洋地理环境、 海洋水文气象、基础数据建设保障以及海洋工程建 设、搜索救援、导航定位信息服务。在与我国利益 相关的深远海域, 加快建立深远海域水文信息大数 据系统，为权益维护提供信息支持。

（5）深海安防系统主要包括深海固定监测网、 大面积机动监测网等深海警戒监测设施, 以及执行 警告、干扰、拦截、驱离任务的深海防卫设施, 由 此满足重要海域水下安全防护、深水重要设施防护、
以及反潜预警的能力需求。

\section{四、关键技术分析}

\section{1. 深海探测技术}

发展新型探测、深海多平台探测、组网协同探 测技术，大幅提高探测范围；发展新型持久机动 + 固定式深海探测技术, 加强深海要道监控能力; 发 展水下/深海无人平台组网探测技术, 提升大范围 持久机动多维网络监视侦察能力; 加强有人 + 无人 系统平台的协同探测技术, 建立多维空间网络无人 值守能力 [11]。

\section{2. 深海通信技术}

构建海底多元化网络化体系，拓展跨介质等新 型技术运用。发展传输速率大、传输距离远、可靠 性高的深海水声通信传输新手段和新装备, 综合利 用海光缆、浮标、水声通信组网, 借助水下无人平 台作为移动中继节点, 实现广阔海域范围的水下信 息传输; 整合广阔海域范围内的各种平台、系统和 岸基基站等通信资源，构建多平台、多手段、多元 化、网络化、体系化的深海信息传输系统, 为构建 从深海到太空的一体化体系提供更多的通信支持。

\section{3. 深海导航技术}

发展水下地磁匹配导航技术，根据载体所在位 置的地磁场总量或三分量信息、地磁图信息, 获得 精确的导航信息; 发展全球海洋水下定位技术，通 过水声通信结合卫导导航系统, 为深水平台提供类 
似全球定位系统（GPS）/中国北斗卫星导航系统 (BDS) 的精确定位能力; 发展量子导航技术, 提 高导航精度; 发展探测 / 通信 / 导航一体化智能信 息处理技术。

\section{4. 深海作业控制技术}

发展深海作业控制体系设计与深海数据资源建 设、多源信息智能处理与按需保障、深海平台资源 智能管控、协同感知与任务动态规划、集群作业协 作与自主控制、深海海洋特性、目标特性库管理等 技术，构建深海立体透明感知、跨域信息共享、安 全可靠的智能化深海装备体系。由此建立深海装备 单平台、多平台、集群的多级综合集成与作业控制 能力，支撑深海信息体系和深海数据资源体系的建 设和应用。

\section{五、发展建议}

在我国 “深海进入、深海探测、深海开发”三 步走发展战略实施过程中, 高效安全的深海信息体 系始终是深海开发利用的关键支撑。立足基本国情、 技术现状和未来需求, 针对性地提出以下发展建议。

\section{1. 加强深海信息体系顶层规划}

加强顶层设计, 注重体系协调发展, 提升深海 体系能力。发展深海探测、导航、通信系统, 发展 资源管控、任务规划、作业管理决策、指挥控制任 务系统, 发展自主智能航行、自主智能作业、自主 智能防卫系统, 加强深海数据体系工程和平台自主 能力建设; 发展有人/无人协同、无人集群协同、 跨体系协同（协同态势感知与评估、协同任务分配、 协同航路规划、协同航行控制、协同智能决策）系 统, 加强平台协同自主能力建设。

\section{2. 加强深海装备型谱规划}

规范信息装备型谱, 指导系列化的设备研制, 适应不同规模、不同任务的深海装备部署要求。建 立信息收集、信息交换、信息控制等方面标准规范, 支持体系内部、体系之间的综合集成。

\section{3. 加强关键技术攻关和设备研制}

提前布局制约体系发展的重点攻关方向, 加强 量子探测、多基地组网探测，水下综合导航定位授
时、重力场导航，以及平台自主智能控制、集群联 合感知与智能自主协同、海洋大数据分析利用等关 键技术研究，为深海设备发展和体系建设提供关键 支撑。

\section{参考文献}

[1] 汪品先. 深海的机遇与中国的选择 [J]. 学术前沿, 2017 (18): 4-11.

Wang P X. The opportunities in the deep sea and China's choice [J]. Frontiers, 2017 (18): 4-11.

[2] 李晋, 姜晓轶. 助力海洋强国建设: 海洋信息互联互通、深度融 合、智慧应用一2018中国海洋信息技术高端论坛会议综述 [J]. 海洋信息, 2018, 33(3): 6-10.

Li J, Jiang X Y. Promoting the construction of marine power: Ocean information interoperation, deep integration and smart application-Summaries of the China ocean information technology forum 2018 [J]. Marine Information, 2018, 33(3): 6-10.

[3] 韩树平, 程玉胜. 美国水下探测系统的发展及现状 [J]. 当代海 军, 2011 (7): 24-29.

Han S P, Cheng Y S. Development and current situation of U.S. underwater detection system [J]. Modern Navy, 2011 (7): 24-29.

[4] Ewing D. Jane's underwater warfare systems 2011-2012 (23rd edition) [M]. London: Jane's Information Group, 2011.

[5] 张羽, 宋积文, 陈胜利, 等. 海洋信息装备发展现状及重点 [J]. 海 洋信息, 2018, 33(3): 62-65.

Zhang Y, Song J W, Chen S L. The development and key point of China's marine information equipment [J]. Marine Information, 2018, 33(3):62-65.

[6] United States Navy. Autonomous undersea vehicle requirement for 2025 [R]. Washington DC: United States Department of Defense, 2016.

[7] Defense Science Board. Next-generation unmanned undersea systems [R]. Washington DC: Office of the Secretary of Defense, 2016.

[8] United States Department of Defense. Unmanned systems roadmap 2017-2042 [R]. Washington DC: United States Department of Defense, 2018

[9] DARPA. Positioning system for deep ocean navigation (POSYDON) [R]. Virginia: DARPA, 2015.

[10] 杨智栋, 李荣融, 蔡卫军, 等. 国外水下预置武器发展及关键技 术 [J]. 水下无人系统学报, 2018, 26(6): 521-526

Yang Z D, Li R R, Cai W J, et al. Development and key technologies of preset undersea weapon: A review [J]. Journal of Unmanned Undersea Systems, 2018, 26 (6): 521-526.

[11] 王君. 支持水下网络中心战的信息系统探讨 [J]. 指挥信息系统 与技术, 2010, 1(5): 6-8.

Wang J. Investigation into underwater net-centric warfare information systems $[\mathrm{J}]$. Command Information System and Technology, 2010, 1(5): 6-8. 